\title{
For Some Histories of Greek Mathematics
}

\section{Journal Article}

Author(s):

Wagner, Roy (i)

Publication date:

2009-12

Permanent link:

https://doi.org/10.3929/ethz-b-000121577

Rights / license:

In Copyright - Non-Commercial Use Permitted

Originally published in:

Science in Context 22(4), https://doi.org/10.1017/S0269889709990159 


\title{
FOR SOME HISTORIES OF GREEK MATHEMATICS
}

\author{
ROY WAGNER
}

\begin{abstract}
This paper reviews Reviel Netz' interpretation of classical Greek geometry, and offers a Deleuzian, post structural alternative. We import Deleuze's notion of haptic vision from its art-history context to propose an analysis of Greek geometric practices, which serves as counterpoint to their linear-modular cognitive narration by Netz. Our interpretation highlights the relation between embodied practices, noisy material constraints and operational codes, and sheds some new light on the distinctness and clarity of Greek mathematical conceptual divisions.
\end{abstract}

\section{Statement of Purpose}

Much historical research is about unlearning contemporary anachronistic knowledge. Its purpose is to articulate, based on textual and material evidence, what actually took place in the past. But the things we take for granted keep changing, and so do the anachronisms we must unlearn. That's why historical research can never rest. And yet, if we unlearn everything suspect as anachronistic, we must also unlearn our contemporary language, and risk remaining mute; we might end up with nothing but reproductions of material and textual evidence. So the transparent reconstruction of a purely objective past must yield to a critical economy of anachronisms.

This economy must be critical, because not all forms of unlearning are of equal value. We might, like Zeuthen (1965), unlearn geometrical Greek practices to retrace geometrical algebra, the algebraic thinking that the Greeks allegedly only

This paper is part of the author's Ph.D. dissertation written in Tel Aviv University under the supervision of Prof. Anat Biletzki and Prof. Adi Ohpir. I would like my advisors and Prof. Sabetai Unguru for their helpful comments. 
presented as geometrical. We might, like Unguru (1975) unlearn geometrical algebra to retrace strictly geometric conceptions. Both approaches help us interact with Greek texts, and produce more or less durable truths. But while Zeuthen reaffirmed the algebra that his contemporaries already knew, Unguru challenged us with new mathematical horizons. I believe that the latter is of considerably more value to contemporary thought.

We will therefore experiment here with unlearning. We will attempt to unlearn historian Reviel Netz' linear and modular narrative of Greek mathematics' historical cognitive method. This is a narrative of mathematical production as a sequence of clearly delimited and highly coded practices of drawing, lettering, speaking and writing. Instead we will try to learn into Greek mathematical production Deleuze's interpretation of the practices of painter Francis Bacon. ${ }^{1}$ We will apply this interpretation to Euclidean and subsequent classical Greek mathematical practices of drawing diagrams and constructing rigorous proofs. Concisely put, our interpretation will situate these highly evolved mathematical activities at various levels between materially constrained embodied gestures and rigorous optico-linguistic codes, and as inseparable from accidental and irrational 'noise'. What binds these levels together is what Deleuze calls haptic vision and the logic of sensation. We then apply this approach to reinterpret the Greek division between different kinds of magnitudes.

The interpretation offered here has much to do with seeing various different orders in diagrams. In this respect it has to do with the analysis of multiplexity in Dynkin diagrams by Lefebvre (2002) and with the useful ambiguity ${ }^{2}$ that

\footnotetext{
${ }^{1}$ Deleuze regularly mentions mathematics in his writing, drawing mainly on Lautman and Cavaillès. The main references are Deleuze (1994), where he considers Leibniz' differentials, Deleuze (1990), where he builds on notions of differential geometry, and Deleuze \& Guattari (1987), where the authors appeal to Riemann's work. More on Deleuze and mathematics is available in Duffy (2004). As for painting, Turner (1997) provides a discussion of some of Deleuze's ideas relevant for this paper. For a more general discussion of Deleuze and painting see Bogue (2003).

${ }^{2} \mathrm{I}$ apply the convention of rendering quotations in boldface. All quotations are in boldface, and everything in boldface is a quotation.
} 
Grosholz (2007) finds in the diagrams of Leibniz. The purpose of this paper, however, is to situate this multiple view in an embodied practice of geometers as they draw diagrams and prove theorems. As such it has more to do with ethnomethodological and phenomenological studies of mathematical practice, such as the classroom observations of Radford (2006) and researcher observations of Sha (2004). But this paper proposes a philosophical language to describe the practice of working on a geometric problem, rather than an ethnomethodological description of mathematical work or a phenomenological research into how geometric practice emerges from more elementary intentional attitudes. ${ }^{3}$

It has been argued that my approach does not live up to the objective and rational reduction ideals of scientific epistemology. To the extent that this is indeed the case, it is because I find that contemporary forms of objectivity and rationality are too restrictive. They tend to neglect embodied standpoints and the force of parasitic noise in knowledge formation. ${ }^{1}$ But philosophy, at least the kind inspired by Deleuze, need not make metaphysical, metapsychological or scientific claims. It is no more abstract than its object. It is a practice of concepts, and it must be judged in the light of the other practices with which it interferes (Deleuze, 1989, II,280).

I don't claim that the economy that I offer here - unlearning a modular cognitive approach and learning one that may part with some forms of objectivity and rationality - is any less anachronistic or any more scientific than Netz'. The value of the interpretation presented here is its challenge to contemporary knowledge. The application of contemporary ideologies to past texts is not meant to reconstruct a past message in its 'original' form, but to render the limitations of

\footnotetext{
${ }^{3}$ The problematic of this paper is not that stemming from Husserl's phenomenology and his Origin of Geometry, either in its original form, or as interpreted by Derrida (1989). There one is concerned with how a concrete worldly practice of spatial orientation and measuring opens into the infinity of possibilities implicit in a system of formal axioms, and the subsequent potential infinity of other systems of axioms. Here I am concerned with the already axiomatised geometric practice, which nevertheless overflows attempts to reduce it to a modular and linear narrative of a cognitive method, and depends on what supposedly lies outside formal reason.
} 
contemporary ideologies more manifest. Whether or not this is history, this is, I think, a worthy task.

\section{First movement: Articulation of the code}

Greek geometric proofs include diagrams and texts. The point of departure for historian Reviel Netz is the observation that Greek mathematical texts cannot function without their lettered diagrams (geometric diagrams with some of their elements indexed by letters). Indeed, many geometric relations are left ambiguous or unspecified by the text, and depend on a diagrammatic determination. In the opposite direction, such relations as parallelism and size are often wrongly depicted by diagrams. My argument, writes Netz, that text and diagram are interdependent, means that many assertions derive from the combination of text and diagrams (Netz, 1999, 27).

Netz notes further that even arithmetical propositions, where diagrams are redundant, for they no longer represent the situations discussed (Netz, 1999, 41), persistently include diagrams. Following Mueller's suggestion that the diagram plays no real role in some arithmetic proofs except possibly as a mnemonic device for fixing the meaning of the letters (Mueller, 1981, 67), Netz asserts that arithmetic diagrams reflect a cultural assumption, that mathematics ought to be accompanied by diagrams (Netz, 1999, 42). The presence of the diagram is therefore not strictly representational or illustrative. Its accompaniment is forced upon the text.

Text and diagrams then form distinct strata of knowledge, which intertwine to from a new surface of knowledge, the surface of Greek mathematics. Rather than one of them governing the other, the text and diagram present, let us say, a cohabitation (Netz, 2004a, 171). A diagram or text alone are undercoded. It is only together that they allow each other to be decoded.

But how does this cohabitation operate? According to Netz, the diagram is relied upon as a finite system of relations ... It is limited in space; and it is discrete. Each geometrical proposition refers to an infinite continuous set of points. Yet ... the lettering of the diagram ... turns it 
into a system of intersections, into a finite manageable system (Netz, 1999, 34-35). This finite system, accompanied by a highly formulaic and restricted Greek mathematical language produced from a few simple building blocks, allowed the simplification of the universe, and contributed towards making the inspection of the entire universe possible (Netz, 1999, 158, 266). ${ }^{4}$

According to Netz those finite and systematic simplifications were schematic, unpainterly diagrams. Non circular curved lines, for example, were probably drawn as if they consist of circular arcs (Netz, 1999, 17-18); sizes and perspectives were not always respected. This may recall Deleuze's quoting Paul Sérusier's description of abstract painting as reducing all forms to the smallest number of forms of which we are capable of thinking - straight lines, some angles, arcs of the circle. We obtain what Deleuze calls "digital", not in direct reference to the hand, but in reference to the basic units of a code (Deleuze, 2003, 92).

\section{Second movement: Manual flow}

But Deleuze explains that even the units of abstract painting are aesthetic and not mathematic, inasmuch as they have completely internalised the manual movement that produces them (Deleuze, 2003, 92). The purpose of this section is to show that it would be wrong to reduce Greek diagrams and texts to a framework of codified, "digital" articulations, and explain how mathematical diagrams too depend on internalising the manual movement that produces them. To do that we will survey (and rule out) several kinds of movements.

To find movement in Greek geometry we do not have to resort to such elaborate kinematic constructions as Archytas' doubling of the cube. Even the very first

\footnotetext{
${ }^{4}$ In his review, Latour (2008) highlights this breakthrough aspect of the work of Netz: the reconstruction of how a world was processed to the point of being subjectable to a rigorous analytic method. My main reservation from Latour's opening statement that Netz' The shaping of deduction is the most important book of science studies to appear since Shapin and Schaffers Leviathan and the Air-Pump is that I consider Netz' The transformation of mathematics an even better candidate for the title.
} 
congruence theorem, Proposition I.4 of the Elements, requires that one triangle be applied or superposed on another (Heath's and Joyce's translations respectively), and that points be placed on one another. Since this proposition underlies so many of the propositions of the Elements, this kind of movement latently applies to most of Greek geometry (the displacing of triangles into a special relative position for proving the Elements' Proposition VI.15 poses a similar challenge).

Explicitly moving geometric elements are very rare in the Euclidean corpus. But while Mueller, following Heath (1956, Vol.I, 225), finds that there is very little evidence that Euclid found such movement problematic (Mueller, 1981, 23), Taisbak clarifies that this motion is not some manual movement within the geometric plane, but a conceptual motion from a virtual outside into the actual plane (Taisbak, 2003, 94).

Since this first form of motion is not a manual movement, let's turn to a second kind of motion built into Greek diagrams. This is the motion of variable positioning of some letters on diagrams. I refer to cases where we are asked to Let some point be taken on the circle, $A(\mathrm{Netz}, 1999,22)$, or Let a chance point be taken on $A B$ (Netz, 2004b, 77). Those points may be moved through various locations in the diagram, and the range of possibilities spreads a complex array of motions. This kind of motion is best reflected, I believe, by the Java applets in Joyce (1988) (an online edition of the Elements), which allow the interactive reader to manipulate diagrams while maintaining the geometric relations relevant to the proposition and the proof. The diagram is no longer static; it becomes a moment in a flow.

But this second motion as presented in Joyce's edition depends on an extremely modern rendering of the Elements. There is no evidence that manipulating diagrams in this way (even only mentally) belonged to the practice of Greek mathematicians. Even worse, these motions, especially when coded into Java applets, only serve the claim that mathematical motion is codable. Joyce turns Greek diagrams from discrete to continuous, but they remain perfectly codified. 
Let's try, then, a third candidate for uncoded manual movement. The manual aspect of Greek diagrams becomes explicit, when we recall that much of Greek mathematics is about constructions, rather than theorems. Constructions have to do with the actual manipulation of drawing devices. Greek mathematical texts rarely suggest optical motions of drawn elements, but is explicit about going through the motions of manual drawing.

Nevertheless, this motion, performed by what Taisbak (2003) calls the helping hand, is still codified by postulates and propositions. To venture beyond such codified and highly regulated motion we must observe an interesting tension between how diagrams are drawn in principle and in practice. Netz argues that in the second proposition of the first book of the Elements, when an equilateral triangle is constructed in the course of the proposition, one is faced with a dilemma. Either one assumes that the two auxiliary circles required for the construction have been constructed as well - but how many steps further can this be carried, as one goes on to ever more complex constructions? Or, alternatively, one must conclude that the so-called equilateral triangle of the diagram is fake. Thus the equilateral triangle of Proposition I.2 is a token gesture, a make-believe. It acknowledges the shadow of a possible construction without actually performing it (Netz, 1999, 54).

The Greek diagram therefore includes a double drawing gesture: the in principle gesture of coded rigorous ruler and compass rendering, and the practical imprecise drawing. The movement is "digital"ly codified in principle (and, where complex diagrams are concerned, only in principle), but manual in practice. This double gesture must not be ignored. To that we add Netz' footnote to the quotation above, which recalls that the text simply says 'let an equilateral triangle have been set up on [the line]', no hint being made of the problem I raise. The distinction between what Deleuze calls "digital" and manual movements are not reflected by the Greek mathematical text. They exceed the facade, but are inherent to the practice. 


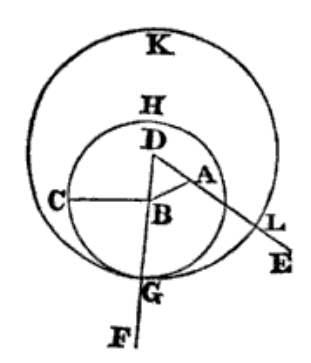

Figure 1. The Elements, Proposition I.2: To place at a given point (as an extremity) a straight line equal to a given straight line (All figures from the Elements are taken from the 1838 edition of Robert Simson's translation by Desilver, Thomas \& co. from Philadelphia and the 1860 edition of John Playfair's translation by J.B. Lippincott \& co. from Philadelphia. Both editions are scanned by Google Book Search. All references from the Elements are quoted from Heath (1956)).

\section{Third movement: Retracing the narrative}

But while Netz is not very interested in the manual movement suggested above, he is concerned to add another kind of motion to the Greek mathematical text. I do not mean simply such motions as sliding rulers, transformations of ratios and falling points (Netz, 2004b, Ch. I, §3). I am referring here specifically to the cognitive motion of narrative.

When Netz brings, for example, a translation of an Archimedean argument, he interweaves Archimedes' static language into a sort of mystery-action narrative of discovery. We have clues; a thought suggests itself; we are led by questions (such as But how to get the rectangle?); we seek and find instruments, and we reach triumphant exclamatives such as But wait - we can arrange that! (Netz, 2004b, Ch. I, §3).

Here things get dodgy. The purpose of Netz' reconstruction is to refute Heath's algebraic reconstruction of Archimedes' geometry. But the dodgy thing is that in trying to refute Heath's anachronistic interpretation, Netz imposes on Archimedes' process of discovery a structure remarkably similar to a modern narrative. This is no innocent reconstruction. A narrative is not a neutral stylistic choice. It imposes (in its simplest, most common forms) a linear order of events, precise starting and 
endpoints, specific sets of relations, and concrete modes of encoding and deriving information. ${ }^{5}$

Indeed, imagine that someone tries to reconstruct Archimedes' process of discovery in Homeric epic hexameter, or via scholastic questions, or as a Hollywood script. Such reconstructions may obviously result in anachronisms. Narrative form imposes significant loss (just as formal logic robs mathematical language of many nuances and non-constative expressions, and generative syntax robs language of the plethora of 'non-grammatical' expressions), and links past mathematical texts to a structure that isn't demonstrably there. Structuring is a practice that extracts from a text what may have never taken place outside the fact of reconstruction. ${ }^{6}$

I will give just one concrete suggestion as to how narrative form might reform history. Typical contemporary narrative form, with its determination of closure, leads Netz to assume that Archimedes solved the problem that he had set out to solve. This precludes the possibility that, perhaps, Archimedes derived the solution indirectly from a different context. This conjecture might explain why Archimedes transformed the original spherical problem into a problem that depends on an entirely different diagram. No evidence suggests that Archimedes' process of discovery is better described by contemporary narrative than, say, by something resembling Joyce's Ulysses (if my professional testimony is worth anything, mathematicians at least contemporary ones - rarely make discoveries by following narratives).

Deleuze explains that the diagram need not have a story to narrate. The figurative, representational or illustrational reduction of diagrams would imply the relationship of an image to an object that it is supposed to illustrate; but it also implies the relationship of an image to other images in a composite whole that assigns a specific object to each of them. Narration

\footnotetext{
${ }^{5}$ Cf. Steinbeck's following comment in his Travels with Charlie concerning a break he took from his travels in Chicago: Chicago broke my continuity. This is permissible in life but not in writing. So I leave Chicago out, because it is off the line, out of drawing. In my travels, it was pleasant and good; in writing it would contribute only a disunity (Steinbeck, 1962, 95).

${ }^{6}$ An important reference in this context is Starobinski (1979).
} 


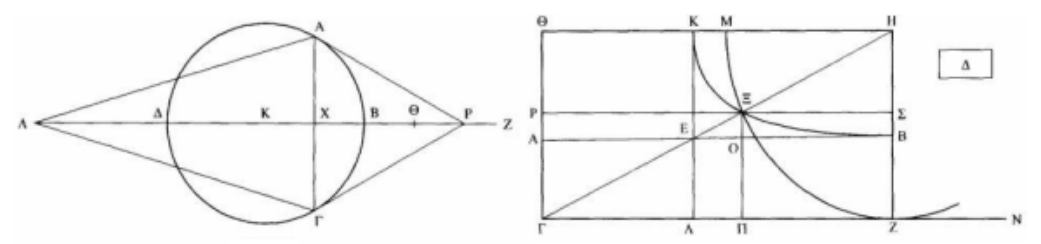

FIGURE 2. Archimedes' diagram presenting the problem (left) and the diagram used to solve it (right) (Netz, 2004b)

is therefore the correlate of illustration. But if A story always slips into our reconstructions, it is not because it was actually there, but in order to animate and validate our conception of a geometric text as an illustrated whole (Deleuze, $2003,6)$. Doubtless one could say that the diagram is the possibility of various narrations at the same time. But this is because the diagram itself, as we will attempt to learn, is beyond all narration (Deleuze, 2003, 59).

Now I do not reproach Netz for his anachronistic narration. Netz' narrative proved extremely helpful in my dealing with Archimedes' argument. But to an extent, so did Heath's algebraic anachronism. Gadamer taught: the text, whether law or gospel, if it is to be understood properly, i.e. according to the claim it makes, must be understood at every moment, in every particular situation, in a new and different way. Understanding here is always application. Indeed, only the person who allows himself to be addressed - whether he believes or whether he doubts - understands (Gadamer, $1975,275,297)$. If a historian fails to impose on texts the anachronistic language that would allow her or him to become an addressee, these texts will remain intractable. But since history is an economy of learning and unlearning, I will suggest another arrangement of this economy, which may allow a different set of addressees to understand and apply Greek mathematical thought. ${ }^{7}$

The previous sections have attempted to unlearn the reduction of diagrams to "digital" coding. In this section we have attempted to unlearn the practice of

\footnotetext{
${ }^{7}$ This is the project of Pierre Menard, who has enriched, by means of a new technique,
} the hesitant and rudimentary art of reading: the technique is one of deliberate anachronism and erroneous attributions (Borges, 1962, 54). 
narrating diagrams. Greek diagrams are able to break with representation, to disrupt narration, to escape illustration, to liberate the Figure. We are after another type of relationships. We will go on to call these new relationships matters of fact, as opposed to intelligible relations (of objects or ideas) (Deleuze, 2003, 6-7). But we are not there yet. More must be learnt before we can learn into Greek diagrams that which Deleuze above baptised Figure and matters of fact.

\section{Fourth movement: Erasing, RedraWing}

Netz offers an ingenious and fascinating analysis of the lettering of Greek diagrams, but here I can only cite his succinct summary of the Greek mathematical sequence of production. Greek propositions originated in many ways, but the most common was to draw a diagram, to letter it, accompanied by an oral dress rehearsal - an internal monologue, perhaps — corresponding to the main outline of the argument; and then to proceed to write down the proposition as we have it (Netz, 1999, 86). Deleuze describes a sequence of production involving another kind of diagrams, that of painter Francis Bacon, as follows: one starts with a figurative form, a diagram intervenes and scrambles it, and a form of completely different nature emerges from the diagram, which is called the Figure (Deleuze, 2003, 125). I will attempt to explain Deleuze's terms and justify learning them into Netz' narrative.

The common use of the term diagram by Deleuze and by Netz is mostly accidental. For Deleuze the diagram is not a neat and coded geometric illustration. For Deleuze the diagram is a bunch of marks, traits which are irrational, involuntary, accidental, free, random. They are nonrepresentative, nonillustrative, nonnarative. They are no longer either significant or signifiers: they are a-signifying traits (Deleuze, 2003, 82). These marks disrupt the representational-narrative painting, and open it up to something different.

But how does this latter diagram relate to Greek mathematics? Netz comments on the difficulties and preparations involved in drawing geometric diagrams with the means available to the Greeks. His own experiments with sand and ashes, 
wetted or not, were unmitigated disasters (Netz, 1999, 15). Working with whitewashed plates of wood, Netz explains, required significant advance preparation. Netz concludes that ad-hoc redrawing of geometric diagrams must have been a difficult task, and therefore diagrams must have been drawn just once during the process of proving, before they were lettered, accompanied by an internal monologue, and the subsequent writing down of the proof.

But this conclusion strongly depends on placing the analysis in the scene of communication. My own experiences of drawing with a stick on dry ground or wet sand, or even scratching a relatively smooth limestone surface with a pebble, were not so unhappy, as long as my purpose was to think with a diagram. Wax tablets might have served as an even more viable medium. But Archimedes seems to have been content with much less. Plutarch, quoted by Unguru \& Rowe (1981-1982, II,5), reports that Archimedes even used to draw the figures on his belly with the scraper when his servants rubbed him down with oil. ${ }^{8}$

True, complicated diagrams would be messed up very quickly given such means. But I personally can't retrace some of the more elaborate drawings from Netz' books even with pen and paper. This fact does not mean, however, that I can't use handdrawn, messy approximations of those diagrams for reflecting on problems. What this does mean is that at some point the diagram begins to smudge, and attempts at correction end up making an even bigger mess. This is precisely where the diagram in the sense of Deleuze/Bacon irrupts. Lines accidentally superimpose; erasure marks seem like lines; an accidental stroke of the stick or the pen suggests a shape inside the diagram; the motion of the belly undoes features of the diagram that Archimedes draws on it with a scraper; a soldier suddenly intervenes to disturb one's circles... Eventually, the diagram must be discarded and redrawn. And redrawn, and redrawn, and redrawn

But Netz does not include such redrawing or retracing in his narrative. For him the letters were set in Greek diagrams once and for all after a rough idea

\footnotetext{
${ }^{8}$ This may sound highly fanciful, but as a mathematician I've witnessed and experienced occurrences not very far removed, such as enthusiastic students drawing or writing on their forearms, when paper was not readily available.
} 
for the proposition has been formulated, but before writing down the text (Netz, 1999, 85). He acknowledges the suggestion that the author drew many different diagrams, each with different ... attachments of letters to elements in the diagram. But he believes that it was very rare that anyone changed the lettering in the diagram after it was first drawn ... If you change your diagram, you must change your text accordingly. You must go through some proof-reading. And as many readers will know from experience, this is a very, very difficult sort of proof-reading to do. It is very difficult not to leave behind mistakes (Netz, 1998, 35). Netz admits, of course, that There are many mistakes in the manuscripts for letters, but he claims that these are all obvious scribal mistakes (Netz, 1998, 35), and not the residues of re-lettering. However, there's no telling whether the lineages of missing manuscripts between antiquity and the middle ages included as many corrections as scribal mistakes.

The difficulty of proof reading brought up by Netz is genuine, but having a lettered diagram at hand would have actually facilitated the process. Furthermore, the proof reading argument is relevant only if we believe, like Netz, that a proof was written down immediately after the lettering (which was accompanied by an oral rehearsal). But Netz' arguments do not preclude the erasure and relettering of diagrams at a stage preceding the scene of writing a proof or recording a diagram for communication; there, arguments may have been embodied in a sequence of drawing motions rather than in written text - a sort of lettering avant la lettre.

\section{Fifth movement: Speaking to oneself}

But should we really incorporate Deleuze's notion of diagram, those forced involuntary, accidental, free, random marks caused by failed and repeated reproductions, into our interpretation of mathematical practice? To answer affirmatively I will interject yet another anachronistic quotation - that of Einstein in a famous letter to Hadamard $(1973,147-148)$. At Hadamrad's request to know what internal or mental images, what kind of "internal word" mathematicians make use of; whether they are motor, auditory, visual, or 
mixed, Einstein replies: The psychical entities which seem to serve as elements in thought are certain signs and more or less clear images which can be "voluntarily" reproduced and combined ... this combinatory play seems to be the essential feature in productive thought - before there is any connection with logical construction in words or other kinds of signs which can be communicated to others. Einstein then goes on to explain that The above mentioned elements are, in my case, of visual and some of muscular type. Conventional words or other signs have to be sought for laboriously only in a secondary stage, when the mentioned associative play is sufficiently established and can be reproduced at will.

Now there are many issues with this testimony beyond the fact that Einstein was no ancient Greek. What is this that can be "voluntarily" reproduced, but is yet to be reproduced at will? And how can we trust what Einstein himself claims to be not quite within full consciousness (in fact, Einstein rejects in his letter Hadamard's use of this term)? We can trust, however, the observable material muscular component of this practice, which Hadamard and Einstein were so perceptive to include. The fact of drawing, with one's arm (using a pen), with one's entire body (using a stick or a scraper) integrates the body into mathematical practice. It is no longer an abstract mental act. It is a process of contractions, rhythms, physical motility. Into the Greek geometric diagram irrupts a language of relations, which consists of expressive movements, paralinguistic signs, breaths and screams (or, to be less dramatic, sighs of frustration) and so on (Deleuze, 2003, 93).

The marginally conscious component of this production, that which precedes the established associative play that can be reproduced at will shows that It is a mistake to think that the painter, or the geometer drawing diagrams, works on a white surface ... If the painter were before a white surface, he could reproduce on it an external object functioning as model, but such is not the case. The painter has many things in his head, or around him, in his studio. Now everything he has around him is already in the canvas, more 
or less virtually, more or less actually, before he begins his work (Deleuze, $2003,71)$. So it is not only the material contingencies of drawing discussed in the previous section that disrupt a rational coding of Greek diagrams, but also those marginally conscious, marginally reproducible psychical entities that are in the geometer's head, or around him. But in order not to force Einstein's dubious psychical entities on Netz, we must ask what, within Netz' own narrative, makes this noise? The answer is, of course: speaking to oneself.

Recall Netz' claim that before proving and after drawing, lettering is accompanied by an oral dress rehearsal - an internal monologue, perhaps (Netz, 1999, 86). Netz confines the internal monologue, and embeds it within a linear chain of externalised practices proceeding from drawing through lettering to writing. But the internal monologue, like redrawing and erasing diagrams, like Einstein's associative play not yet reproducible at will, like the accidental, nonillustrative marks of Deleuze's diagrams - all these are not confined moments in a linear chain of events. The internal monologue accompanies the entire process of mathematical production, and is part of the many things in the geometer's head, or around him. The internal monologue is the back-and-forthing stutter that accompanies drawing, lettering, mumbling, writing, and most importantly - erasing. ${ }^{9}$

The reason why Netz erases the moment of erasure from Greek mathematical practice, and forces a narrative sequence of a single instance of drawing, lettering, speaking, and writing, is his explicit commitment to Fodor's cognitive science. Netz agrees with Fodor that the only cognitive processes, which are scientifically tractable, are the supposedly independent automatic modules associated with input/output processes. But he argues that central processes, the intricate nonmodular constituents of thought, while not subject to universal articulation, can be articulated in the framework of specific historic practices.

\footnotetext{
${ }^{9}$ The reader may be familiar with the following (cruel and untrue) joke prevalent among mathematicians: The two cheapest academic disciplines to maintain are mathematics and philosophy. Mathematics, because all a mathematician needs is paper, pencil and eraser; philosophy, because the philosopher doesn't even need the eraser.
} 
Netz believes that There is a method in Greek geometrical use of cognitive resources (Netz, 1999, 6). This method anchors input/output practices to a distinct moment of private internal monologue, which aligns them into a narrative. But this feat depends on tapping into a rather anachronistic, Cartesian image of the internal monologue: something that exists as a determined and confined object in a sequence, enclosed between drawing and writing. The internal monologue as an unbounded repetition of embodied marks that accompany the geometer throughout the creative process is foreclosed. ${ }^{10}$ This foreclosure re-traces the anachronistic erasure by many contemporary cognitive scientists of irrational, nonrepresentative, liminally reproducible traces, whose surface representation is that which Deleuze calls diagram.

Now I don't claim there's anything wrong in reaching into the internal monologue. Netz did, Einstein did, and I certainly do. Indeed, if one refuses to cross into the internal monologue, one has to operate more and more reductions, only to discover that one either cannot say anything of interest, or has in fact never let go of reaching into the internal monologue at all. ${ }^{11}$ But when we tap into the internal monologue, we need not assume that we've gotten anywhere. This private monologue is not an object that can be articulated by a science or a metaphysics. ${ }^{12}$ The internal monologue is rather one of those many productive lacunae or interfaces that allow us to project contingent anachronistic conventions, which are the conditions of language and thought, onto our objects of study in order to validate or to critically rethink these conventions. The internal monologue is, here as in Netz' work, a locus of ideological intervention.

\footnotetext{
${ }^{10}$ The critique of Husserl's internal monologue in Derrida (1979) and the replacement of presence by différance obviously underlie my argument.

${ }^{11}$ e.g. young Wittgenstein, logical positivism, psychological behaviourism, epistemologies that attempt to isolate rigorous sciences from cultural contingency - but sciences do not require such isolation, if only they stop hinging some of their well earned authority and privilege on claims to seize a purely objective truth.

${ }^{12}$ Netz quotes Fodor's famous 'First law of the Nonexistence of Cognitive Science': 'The more global ... a cognitive process is, the less anybody understands it' (Netz, $1999,5)$.
} 


\section{Sixth Motion: Haptic Vision}

Let's recapitulate and integrate. We have attempted to unlearn the conception of Greek mathematical diagrams as abstract, coded and narrative systems. Deleuze would call such systems 'optical'. For manipulating such optical systems a finger (digit) is enough. The hand is reduced to a finger that presses on an internal optical keyboard in a rigid sequence (Deleuze, 2003, 85). We have attempted to learn into Greek diagrams Deleuze's notion of diagram - irrational, random, nonrepresentative marks, which are forced on erased and redrawn sketches by material contingency and by the liminally reproducible entities in the geometer's head, or around him.

When a geometric diagram turns into a diagram in the sense of Deleuze, it may seem as if, in the midst of the figurative and probabilistic givens, a catastrophe overcame the canvas (Deleuze, 2003, 82). This is often a moment of confusion and frustration, but also a moment of detachment. Deleuze's theorisation suggests that in such moments, where the optical space is disrupted, the drawing may break away from its confinement to the surface of inscription, and be absorbed into the body through the hand and eye (or the belly, in Archimedes' case). In fact, those marks referred to by Deleuze as catastrophe have a role in enabling creative situated thinking (cf. Turner, 1997).

But Deleuze does warn us that if we let catastrophe run wild, we get no visual space at all. The drawn space then becomes a space of action painting: a manual and physical space relating embodied motions. To avoid that, Deleuze explains, the catastrophe must not be allowed to eat away at the entire painting; it must remain limited in space and time. It must remain operative and controlled ... The diagram is the possibility of fact - it is not the fact itself. Something should emerge from the catastrophe (Deleuze, 2003, 89). We must now explain how the highly regulated visual-textual products of Greek geometry can emerge from catastrophe.

Bacon, according to Deleuze, follows a third path, which is neither optical like abstract painting, nor manual like action painting (Deleuze, 2003, 90). 
The operative set of asignifying and nonrepresentative lines and zones, line-strokes and color-patches, those elements of what Deleuze calls diagram, its function, says Bacon, is to be "suggestive" ... to introduce "possibilities of fact" (Deleuze, 2003, 82-83). Bacon explains: the marks are made, and you survey the thing like you would a sort of graph [diagramme]. And you see within this graph the possibilities of all types of fact being painted. This is a difficult thing; I'm expressing it badly. But you see, for instance, if you think of a portrait, you maybe have to put the mouth somewhere, but you suddenly see through the graph that the mouth could go right across the face (Deleuze, 2003, 160).

Mathematically recontextualised, Bacon's way would integrate the random, asignifying, nonrepresentative possibilities into mathematical matters of fact: What if we turn this crooked circular arc into a parabola? What can we prove then? What if we replace this extremely thin triangle by a line? What statement would the diagram then reflect? What if we reinject this soldier disrupting my circles into the diagram as the axis of a cone?

These reinjection and emergence, however, do not bring us back from Deleuze's disruptive diagram to a coded, illustrative, narrative diagram. Indeed, through this action ... the visual whole will cease to be an optical organisation (Deleuze, 2003, 83). What emerges is that which Deleuze calls Figure. Such Figure is defined by Deleuze to be itself a shifting sequence or series (and not simply a term in a series); it is each sensation that exists at diverse levels, in different orders, or in different domains ... The levels of sensation would be like arrests or snapshots of motion, which would recompose the movement in all its continuity, speed and violence (Deleuze, 2003, 33, 35). The Figure which emerges from the diagram and its catastrophe relates the elements involved in its generation into a multi-layered space of regulated motion.

The Figure, this visual whole will cease to be an optical organisation; it will give the eye another power, as well as a space to look after (Deleuze, 2003, 83). Deleuze refers to this empowered eye as a haptic eye. This eye goes 
beyond the abstract optical code and the embodied action space. It is that which senses the motions which the Figure went through, which retraces the asignifying and irrational marks involved in its formation, which retains some of the many diagrammatic possibilities that the Figure left unactualised. What has emerged is the formation of a third eye, a haptic eye, a haptic vision of the eye, this new clarity. It is as if the duality of the tactile and the optical were surpassed visually in this haptic function born of the diagram (Deleuze, 2003, 129). Haptic vision is not a mystic construct that I use to elevate mathematical production to the level of artistic thrill. Haptic vision is the capacity to practice diagrams not only as optical and manual, but also as dynamically stratified.

\section{Seventh motion: Looking at Greek diagrams through a haptic eye}

It is finally time to show how haptic vision is manifest in contemporary readings of Greek geometry. Netz' examples and interpretations (with some help from Fried, Unguru and Mueller) provide us with ample opportunity for that.

The Greek text gives such orders as: let a circle have been drawn, or let the given bounded straight line be $A B$ (Netz, 1999, 51-52). These are, as Netz observes, perfect imperatives, orders to have already completed an action. To whom can such an order be addressed? If we do not dismiss these commands as a rhetoric curiosities, then they're directed at an organ that has the power not only to make things happen, but also to sense them as already-having-happened. The haptic eye, as an organ that builds on the manual sensation of drawing, has the capacity not only to recognise lines and letters, but also to draw from past experience the sense of having had something drawn and lettered, and project it on the Figure. Haptic vision includes the capacity to sense in the Figure both a newly given present and a completed past - it is each sensation that exists at diverse levels, in different orders, or in different domains.

But this sensing as completed of that which is being presently given is not static. It has further levels, orders and domains. Suppose we are ordered to Let some point be taken on the circle, $A(\mathrm{Netz}, 1999,22)$, or Let a chance point be taken on $A B(\mathrm{Netz}, 2004 \mathrm{~b}, 77)$. Here we are ordered to sense a point as 
general or as random. To do that we require more than just an observing eye or a drawing hand; we must sense with the given point the possibility of alternative points being taken elsewhere. But haptic vision emerged from the random marks of the diagram. It can retain this sense of randomness in viewing a fixed point. Its retention of catastrophic marks not actualised into facts is a sense of the possible as such. Therefore, if we can, with Netz, see how a given line functions as a variable, it is not necessarily because nothing is known about the real size of the number it represents, as Netz (1999, 268) anachronistically suggests. Instead, this line might be a moment in a shifting series of chance extensions and contractions in past sketches, of which haptic vision retains a sense. To the orders of present and past are added those of the possible, random and general.

Sometimes lines are not only general, but actually mobile. Fried \& Unguru (2001, 69-70) follow Apollonius in stating that a straight line generating some conic surface is moved to generate the conic, even though the diagram is still. If indeed the three diagrams given in the body of the proof ... may be thought of as three "snapshots" of the generation of the surface just described, it is because the organ that watches over them can see, as Deleuze put it, a shifting sequence or series. The diagrams may be indistinguishable except for the labelling, but one can see in the proof and in the diagram the genesis of the relevant geometric objects. Moreover, from a given conic surface one may derive a cone having its base as far as one pleases from the vertex and on whatever side (Fried \& Unguru, 2001, 72). Apollonius does indeed prefer the visually appealing bounded cone over the not-so-easily pictured unbounded conic surface (Fried \& Unguru, 2001, 74). ${ }^{13}$ But he does not give up on the conic surface. His diagrams urge us to imagine a cone being increased from one base to another, or, rather, a sequence of cones with ever increasing bases (Fried \& Unguru, 2001, 74). But from the point of view of the haptic eye this wouldn't be imagining; it would be sensing in the Figure what's retained from

\footnotetext{
${ }^{13}$ The conic surface here is the unbounded, infinitely extended object, whereas the cone is the bounded solid obtained by truncating the conic surface. A cone to a conic surface is like a segment to a line.
} 
past discarded sketches and unactualised possibilities of diagrams. Haptic vision adds to present, past, possible, random and general also the level of motion.

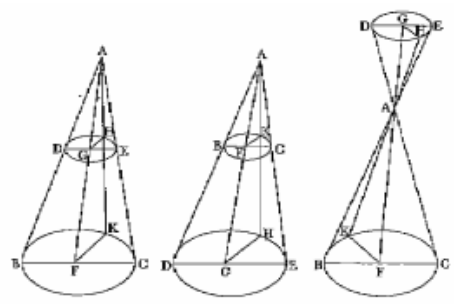

FigURE 3. Apollonius' cones (Fried \& Unguru, 2001)

Mueller quotes Heath quoting Simplicius' report according to which the fifth-century sophist Antiphon claimed that a polygon of sufficiently many sides inscribed in a circle would exhaust (dapanan) the circle (Mueller, 1981, 234). This is precisely the kind of perception that thick-lined material drawing of diagrams and its catastrophes may conjure, and which haptic vision transforms from a manually traced exhaustion of the circle into a stratified shifting sequence or series (and not simply a term in a series) - a series of improving approximations, as in the Figure of the Elements Proposition XII.2. ${ }^{14}$

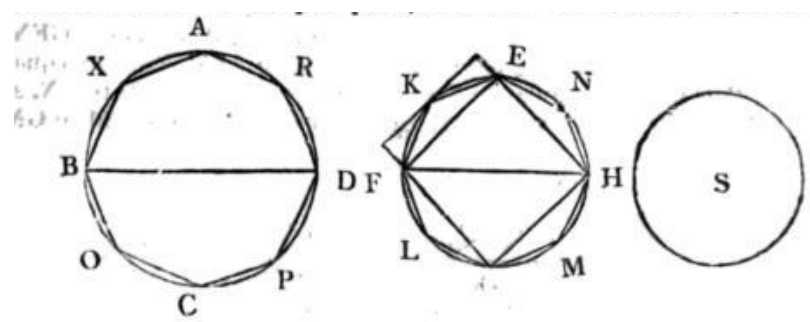

FIGURE 4. The Elements, Proposition XII.2: Circles are to one another as the squares on the diameters.

\footnotetext{
${ }^{14}$ It's more than lines that move in Figures. When we observe with Netz $(1999,27-29)$ an implicit similarity between triangles, it is not by recognising it optically, but, according to Netz, by retracing the unwritten argument that establishes this similarity. We coordinate the various facts involved in retracing the argument for similarity, and we coordinate them at great ease, because the diagram is not optic but synoptic. A still diagram can be read by the haptic eye as a Figure of shifting series of procedural relations excited from the geometer's practice.
} 
Building on both material, manual drawing and coded, optical or "digital" drawing, the haptic eye exceeds the capacities of either. The same Proposition XII.2 of the Elements provides an example, where haptic vision constructs what the eye and the hand cannot construct. The proof of this proposition assumes that given three areas (the square on $B D$, the square on $F H$ and the circle $A B C D$ ), there exists a fourth area, $S$, which satisfies that the ratio between the squares is the same as the ratio between the circle and $S$. In his notes Heath writes that $18^{\text {th }}$ century scholar Simson observes that it is sufficient, in this and the like cases, that a thing made use of in the reasoning can possibly exist, though it cannot be exhibited by a geometrical construction. This is a strange note, given that in the one-dimensional case such assumption was not considered legitimate by Simson, and that Heath spent much text on the construction of a fourth proportional in his note to Proposition V.18. Mueller's analysis suggests quite a few cases of non constructible elements used in proofs (see the index entry for 'constructive' in Mueller (1981)). Endorsing such interpolating constructions requires a vision that goes beyond the geometric code and manual drawing to a continuum of not necessarily actualised possibilities.

Given all that, it should no longer be odd that we can Let the points $A$, etc. be imagined as the points of the angles of the inscribed polygon, even when this polygon is not actually drawn in the diagram of Elements Proposition IV.12. The constitutive and cumulative experiences of erasing and re-drawing endow haptic vision with the capacity to sense lines in the Figure without actually resorting back to the drawing hand.

The same experience enables haptic vision to retrace elements, which are no longer mentioned in either diagram or text. As Netz (2004b, 54) puts it, the readers imagine a watermark underneath Diocles' diagram, which has a sphere ... and two cones, even though Diocles has actually discarded the sphere and the cones from both diagram and text. The cones and sphere are part of what's there in the geometer's head or around him. 


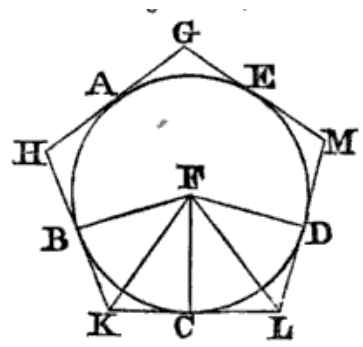

Figure 5. The Elements, Proposition IV.12: About a given circle to circumscribe an equilateral and equiangular pentagon.

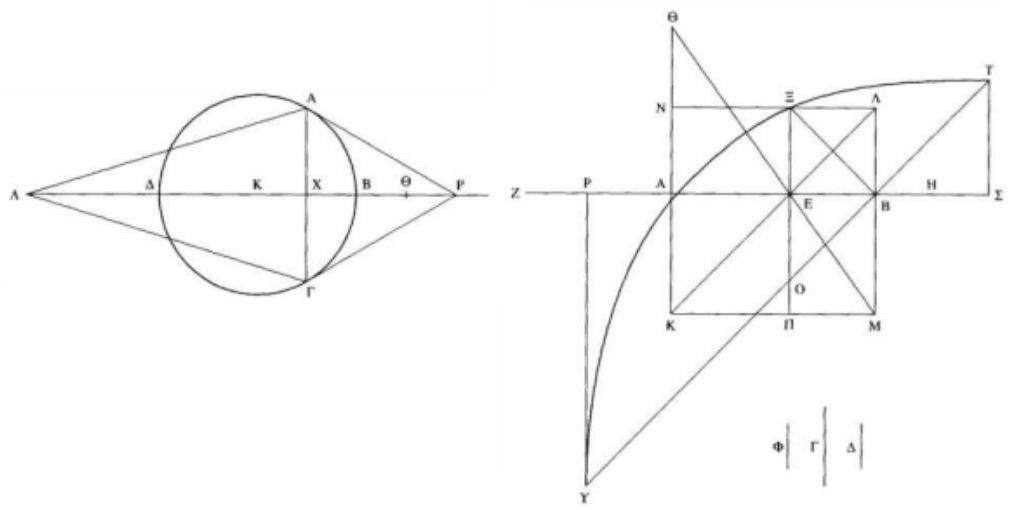

FIGURE 6. Archimedes' diagram presenting the problem (left) and Diocles' diagram that suppresses the circle and cones (right) (Netz, 2004b)

Finally, haptic vision can sense not only what's not constructible and not there, but even the absurd. In Proposition III.10 of the Elements, two circles are drawn intersecting at four points. A generative history of practicing catastrophic marks in messy sketches of crooked circles is what enables haptic vision to integrate this counterfactual accident of representation into a geometric proof. The haptic eye is precisely this capacity to reintegrate the irrational marks of the diagram into the regulated and stratified Figure.

Time and again Netz brings up examples of diagrams with distorted perspectives, wrong rendering of parallels, wrong rendering of ratios between magnitudes, syntactic constructions that suggest geometric relations different from those traced, and virtual constructions of geometric objects that bring together elements from nonadjacent locations of a diagram. All these facts suggest that the organ that watches 


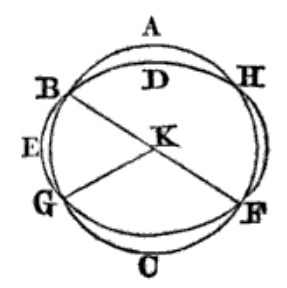

Figure 7. The Elements, Proposition III.10: A circle does not cut a circle at more points than two.

over geometric diagrams must be able to see something different than what's actually written and drawn. Indeed, this is a feature of the haptic vision that emerged from a code subverted by the catastrophes of manual drawing and the internal monologue (those psychical entities from before there is any connection with logical construction ... which can be communicated to others). But to make sense, all this action must be stratified into orders such as past, present, possibility, chance, generality, motion, extension, synopsis, erasure, retracing, interpolation and counterfacticity. Haptic vision operates not by reducing Figures to a new optical code, but by dynamically articulating and communicating the above levels. It must organise these domains of sensation to form the rigorous surface of Greek geometric knowledge.

Haptic vision must not be confused with the all powerful mind's eye. The mind's eye is a construct that's supposed to observe modular and abstract idealities, and is bounded only by the formalities of a logic of perception and cognition. The haptic eye, on the other hand, is constrained by a generative history of embodied sensations. It is the capacity to articulate and recompose levels, orders and domains of sensation into a movement in all its continuity, speed and violence, a capacity regulated by what Deleuze names the logic of sensation.

\section{Eighth Motion: The CRAShing of Dimensions}

In this section I will derive some consequences of the above analysis for an interpretation of one of the main divisions in Greek mathematical conceptualisation: the division between magnitudes of different dimensions, and the division between 
geometric magnitudes and numbers. I will first survey the standard knowledge concerning this division, then point out some new observations concerning the stability of this division, and finally suggest ways of sorting out our understanding of this division in light of the theoretic apparatus presented above.

In his introduction to the second volume of his translation of the Elements, Vitrac $(1994,20-21)$ points out how the study of numbers (positive integers) was considered by some Greek authorities as divided between numbers as such and numbers in relation to each other (ratios), or between the consecutive and the contiguous. Such divisions didn't make it into Greek mathematics as we know it. But the one division that remained in force throughout, according to Vitrac, is the division between the continuous and the discrete, geometry and arithmetic, magnitude and number (Vitrac, 1994, 24).

The Euclidean tradition refused to superimpose the domains of geometry and arithmetic, and did not allow to arithmetically manipulate magnitudes in abstraction of their geometric representation (say, multiply lengths and areas as numbers). Unlike its later versions, classical Greek mathematics is not tinged by this hybrid and forbidden procedure (Fried \& Unguru, 2001, 38). This fact entailed a strict division between magnitudes of different dimensions. Indeed, if the integrity of the principle that magnitudes of different dimensions are distinct would have been weakened, then the way would be open for the formulation of a conception of magnitude ... as generalised number, completely independent of any particular geometrical representation (Unguru \& Rowe, 1981-1982, I,22), consequently tingeing Greek mathematics with the hybrid and forbidden.

Nevertheless, Unguru \& Rowe (1981-1982, I,16) concede that there is no explicit statement in Euclid of the segregation of magnitudes of different dimensions (except in the limited context of Definition V.3, where a ratio is defined as relating two magnitudes of the same kind), and that it is not clear that these matters were even given much thought, at least by mathematicians (as opposed to philosophers). Indeed, so little thought was given to this issue, that all 
propositions concerning magnitudes, regardless of kind, were subsumed under the common signs, terms and proofs of Book V.

Fried \& Unguru $(2001,38)$ further concede that burgeonings of what retrospectively can be recognised as the forbidden practice of magnitudes as numbers may be found in Heron. And while Heron is indeed a later proponent of Greek geometry, we may assume that discussions of the measurement, in explicit numerical terms, of geometrical shapes, would have been conducted in antiquity in this language. There is no reason to suppose Hero's discourse was original to him (the fact that all evidence for this discourse comes from later Greek geometry is explained by the usual reasons of the dates of papyrus survival (Netz, 2004b, 113)). It seems, then, that alongside the highbrow Euclidean tradition there existed a 'vulgar' tradition, which had no qualms about imposing numerical values on magnitudes, and where geometrical objects are treated as possessing a quantitative value and explicitly multiplied by each other (Netz, 2004b, 113). Now, as Netz maintains, Greek mathematicians must have been acquainted with these procedures, which they rejected in practice (possibly without giving this rejection too much thought). But whatever was thoughtlessly rejected, entered, as we shall see promptly, the non-white surface against which Greek mathematicians wrote their proofs.

The careful distinction between inhomogeneous magnitudes such as lines, areas and numbers is usually traced back to the discovery of incommensurables (Vitrac, 1994, 30). Aristotle reconstructs this distinction as predating his contemporary practice of proof. He explains that Alternation, namely that rule prescribing that if $a: b$ is the same as $c: d$ then $a: c$ is the same as $b: d$, used to be demonstrated separately of numbers, lines, solids, and durations, though it could have been proved of them all by a single demonstration. Because there was no single name to denote that in which numbers, lengths, durations, and solids are identical, and because they differed specifically from one another, this property was proved of each of them separately. To-day, however, the proof is commensurately universal, for they do not possess 
this attribute qua lines or qua numbers, but qua manifesting this generic character which they are postulated as possessing universally (Posterior Analytics, A 5, 74a18).

But Aristotle's statement above is false, at least from the point of view of the Elements, where distinct proofs are given for magnitudes and numbers (propositions V.16 and VII.13). Perhaps Aristotle for a moment mistook the similar expression of the two distinct propositions for a unified proof under a single principle. Possibly, the identical diagrams for both propositions allowed (or forced?) Aristotle to lay aside, for a moment, the division that he himself endorsed between continuous and discrete. Quite probably Aristotle's historic reconstruction is imprecise. The development of the ideological divisions and the various distinct or unified proofs may have gone through many diverging and converging paths, two distinct moments of which may have been captured by Aristotle and by the Elements.

In fact, the stability of the distinction between number and magnitude is threatened even inside the Elements. Mueller shows how Euclid carefully made sure (albeit not explicitly) to maintain minimal homogeneity assumptions in proving propositions about ratios. This means that, if a proposition concerning four magnitudes could hold when two of the magnitudes are of one kind (say lines), and the two others are of another kind (say areas), Euclid made sure that the entire proof would hold for such a setting, without ever going through a step which involves a ratio between inhomogeneous magnitudes (say a line and an area). And yet, Proposition V.23 is, as Mueller notes, an exception to this rule. So he writes: I am inclined to think of 23 as an inexplicable exception rather than a refutation of the view that Euclid is generally concerned with minimising homogeneity assumptions (Mueller, 1981, 133). Could the exception be explained by practices in the geometer's head, or around him that didn't give much thought to segregating non homogeneous magnitudes, and that subsumed different magnitudes under common signs and diagrams?

This evidence for the power of the common sign to confuse ideological divisions is not isolated. Mueller (1981, 137-138) demonstrates Euclid's blending of his 
two theories of proportion, that of continuous magnitudes and that of discrete numbers, without bothering to integrate them or link them together. The Greek mathematician occasionally breaches the boundary between magnitudes and numbers without concerning himself with the resolution of ideological issues on his way to mathematical discovery.

There is also evidence of jumping from one-dimensional observations to twodimensional conclusions. We have already mentioned the question of constructing a fourth proportional to three given magnitudes (given $a, b$ and $c$ to find $x$ such that $a: b$ is the same as $c: x)$. The Elements solve this problem for lines, but do not have the means to solve it for general two-dimensional figures. Nevertheless both in V.18 and in XII.2 the general solvability of this problem is assumed (we could accept the opinion of Unguru \& Rowe (1981-1982, II,57) that this was a slip, if it was but confined to a single proposition, and if Mueller hadn't supplied us, as noted above, with further examples for non-constructive manoeuvres).

In order to further evaluate the stability of the division between magnitudes I will explore the relations between explicitly stated methods for establishing ratios of two-dimensional magnitudes and the assumptions made by propositions in book $\mathrm{V}$ that are concerned with such ratios. My conclusion will be that Book V assumes, with no attempt at procedural justification, that for all intents and purposes magnitudes are qualitatively structured like lines.

The definitions that open Book V of the Elements leave the researcher with much to be desired. Definition V.1 reads: A magnitude is a part of a magnitude, the less of the greater, when it measures the greater, and Definition V.4 reads: Magnitudes are said to have a ratio to one another which are capable, when multiplied, of exceeding one another.

What does measure and exceed mean? In the case of line segments all is visually clear. For one line segment to measure another means that if one copies the shorter segment several times side by side, one obtains the longer segment. For one segment to exceed another simply means that the longer covers the shorter with excess. 
But how do we handle two-dimensional figures? Obviously, a figure can measure another even if the latter cannot be broken into several copies of the former, and one figure can exceed another even if the latter does not fit inside the former as is (a thin rectangle needn't fit into a square, even if the latter is larger). Vitrac $(1994,15)$ reconstructs these two-dimensional relations as "imaginarily" articulated, and Mueller $(1981,122)$ reconstructs them as simply conceived. To better understand these conceptions, let us analyse the procedures that the Elements employ to establish magnitude relations.

There are three basic procedures involved in comparing magnitudes. The first is subsumed under Common Notions 2 and 3, which state that If equals be added to equals, the wholes are equal and If equals be subtracted from equals, the remainders are equal. This procedure is used paradigmatically in I.35, where two parallelograms are equal, because they can be represented as two congruent triangles, together with some fixed triangle, and with another fixed triangle removed.

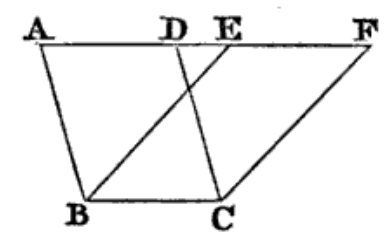

FiguRE 8. The Elements, Proposition I.35: Parallelograms which are on the same base and in the same parallels are equal to one another.

The second procedure for comparing magnitudes is presented in Definition V.5, which states that $A$ to $B$ is in the same ratio as $C$ to $D$ if, when we take equimultiples of $A$ and $C$ (multiply both by any given number), and equimultiples of $B$ and $D$, then the former multiples will either both be greater than the latter respectively, or both equal, or both smaller.

A further procedure for comparing magnitudes is found in Proposition XII.2. Here we encounter the more delicate procedure of exhaustion. To show that figures $A$ and $B$ have a given ratio it is enough to show that the ratio between $A$ and 
anything inscribed in $B$ exceeds the given ratio, and that the ratio between $A$ and anything inscribing $B$ is exceeded by the given ratio.

Let us now check whether the knowledge provided by these means of establishing the equality of magnitudes indeed provides us with whatever's assumed in the proof of a fundamental result: Proposition V.1 (similar problems occur with other propositions in Book $\mathrm{V}$ ). In this proof we have a magnitude $A B$ which is hypothesised to be a multiple of a magnitude $E$. In the proof of V.1 we are ordered to Let $A B$ be divided into the magnitudes ... equal to $E .^{15}$ Now suppose, for example, that one has established that $A B$ is a multiple of $E$ via Definition V.5. In that case all we know from what we have established (namely, that Definition V.5 holds for the ratio $A B: E$ and some integer ratio) is which multiples of $A B$ are greater than which multiples of $E$, which are equal and which smaller. We have, however, no means of dividing $A B$ into components equal to $E$. What we obtain by establishing that $E$ is a part of $A B$ via Definition V.5, and what we assume for proving Proposition V.1 is not immediately compatible. As in Definition V.1, the missing link here is procedurally obvious in the case of line segments, but is unaccounted for in the case of other magnitudes.

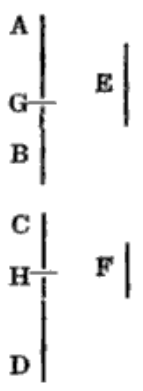

FIGURE 9. The Elements, Proposition V.1: If there be any number of magnitudes whatever which are, respectively, equimultiples of any magnitudes equal in multitude, then, whatever multiple one of the magnitudes is of one, that multiple also will all be of all.

\footnotetext{
${ }^{15}$ Related problems occur with V.8, where we are ordered to perform the simpler task of finding something equal to a magnitude $C$ inside the greater magnitude $A B$.
} 
We would encounter a similar problem if the ratio between $A B$ and $E$ were established by exhaustion. There, all we would know is when some multiples of $A B$ are greater or smaller than some multiples of things inscribing or inscribed in $E-$ nothing more. And yet, no argument would be deemed necessary to subsequently apply Proposition V.1, which proof assumes much more: that $A B$ is decomposable into parts that equal $E$ (what Definition V.5 and exhaustion provide us is indeed enough to produce some proofs of Proposition V.1, but these would not be the proof actually given in the Elements).

In fact, even if we establish the ratio between one magnitude and another using only Common Notions 2 and 3, we do not necessarily know enough to break one into copies of the other. For example, we mentioned that in I.35 the equality between two parallelograms is proved by a simple cut-and-paste procedure. In I.37, the equality of two triangles ( $B A C$ and $B D C$ in the diagram for Proposition I.37) is proved by duplicating the triangles to form parallelograms, and then using I.35. We obtain that the parallelogram $B D F C$ equals the parallelogram $B E A C$, which equals twice the triangle $B A C$. Now, since the cut-and-paste of $B D F C$ in I.35 does not respect its division into the triangles of I.37, we do not have here any means by which to decompose the parallelogram $B D F C$ into two copies of the triangle $B A C$. Nevertheless, Proposition V.1 simply assumes that we have such a decomposition (whether such decomposition may be obtained by other means is irrelevant, because the Elements do not demonstrate a need for any such decomposition).

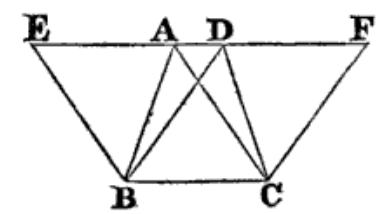

FiguRE 10. The Elements, Proposition I.37: Triangles which are on the same base and in the same parallels are equal to one another.

What we have is only a cut-and-paste procedure to compare a certain doubling of the triangles. If the proof of Proposition V.I were to respect the above manner of establishing ratios, it would have to start by equimultiplying its given $A B$ and 
$E$, so we are in a situation to cut-and-paste one into copies of the other, and then proceed with the original proof. Such a proof, again, can be produced, but is not actually produced in the Elements.

Even if we 'relax' our reading of Proposition V.1, and interpret it as assuming that a multiple of a magnitude can be decomposed into parts, each of which equals that magnitude in whatever abstract sense, without necessarily being congruent to it, we still encounter a problem. In this case we have no problem with the last example, because the parallelogram $B D F C$ can be decomposed into two parts, each equal, though not congruent, to $B A C$. But take for example a segment $A$ divided into 11 parts, each equal to a segment $B$. Then, according to XII.2, the circle on $A$ is 121 times the circle on $B$. But despite the capacity assumed in the proof of V.1, the Elements provide no means for dividing the circle on $A$ into 121 equal parts, even if we do not require these parts to be 121 circles equal to $B$.

So, we see, the assumptions of proofs concerning ratios in Book V depend on more knowledge than is immediately available from the methods for establishing ratios. ${ }^{16}$ The problem is, however, eliminated in the context of line segments, where a simple manual procedure for comparing magnitudes is available. It turns out that the proofs of Book V assume that magnitudes behave like line segments, and that these proofs do not give this assumption any explicit attention (if indeed, as Aristotle suggested, these proofs were once given separately for different kinds of magnitudes, then to confront the above issues these proofs would have had to be much more elaborate than those in Book V). The fact that proofs concerning magnitudes do not simply give a fully justified common treatment to all kinds of magnitudes, but impose the structure of line segments on all other magnitudes, shows that there is a genuine crossing of borders between the realms of magnitudes of different dimensions.

\footnotetext{
${ }^{16}$ The problem is genuine even if we attempt to interpolate some intermediary arguments, since the Greeks believed that a square can be a certain multiple of a circle, while one cannot finitely cut-and-paste circles into squares or vice versa. In fact, even for three-dimensional polyhedra this is not necessarily possible, as shown by Dehn's and Kogan's solutions to Hilbert's third problem. But the Greeks never strayed far enough to encounter this problem.
} 
What kind of conception could justify the assumption that two-dimensional magnitudes behave like one-dimensional magnitudes in the sense that, if one magnitude is established to have an integer ratio to another via the tools available in the Elements, then the larger can be decomposed into pieces equal to the smaller?

One could consider a 'fluid' notion of two-dimensional sizes, where if we 'pour' the content of a certain area we might 'fill up' a certain number of other areas, thereby giving procedural sense to such partitioning. But there is no indication of anything like that in the relevant mathematical literature. A more radical suggestion is to conceive of magnitudes as abstract quantities, but such a conception was convincingly refuted in Unguru (1975) and in Unguru \& Rowe (1981-1982).

Another option is to think of a figure $A$ as bigger than a figure $B$ in terms of being able to cut $B$ into many small pieces, and rearrange their positions so as to fit inside $A$. More precisely, this approach would be based on the fact that even if $A$ is only slightly larger than $B$, then partitioning $B$ into pieces of sufficiently small diameter would necessarily allow to rearrange them so as to fit inside $A$ (regardless of the actual shapes of the pieces).

But this is a modern approach, which is not explicitly present in Greek texts. Greek cut-and-paste arguments always depend on the concrete shapes of their few actual pieces. Moreover, this approach may be useful when one magnitude is larger than another, but does not necessarily work for showing that two magnitudes are equal (say, a circle and a square), and does not resolve the problem of applying the proofs of Book V to ratios established by means of exhaustion. Therefore, such a conception would have to be complemented by a principle along the lines of the one attributed by Philoponus to Bryson: that of which there is greater and less there is also equal (Knorr, 1975, 71), which is not clearly acknowledged by Greek geometers (indeed, if it were, then Bryson's solution for the squaring of the circle would have probably enjoyed a better acceptance). The Greeks had the tools to establish and complete a theory along such lines (the missing component is not more sophisticated than their definition of equal ratios), but assuming that they had such a theory would be a facile anachronism. 
The challenge is to explain the practice of magnitudes as one dimensional in terms of signs, diagrams and inferences, without resorting to excessive abstraction or hypotheses of esoteric knowledge. One needs to explain here manipulations, which can't be operated by the optical and “digital” code, but which, like Deleuze's manual motions and catastrophes, must remain operative and controlled, if we are to emerge from the catastrophe.

I would like to suggest that the diagrams accompanying the proofs of Book $\mathrm{V}$, which represent magnitudes as line segments, should be taken 'literally'; that when Greek geometers watched over two-dimensional figures and considered their sizes, they saw, among other things, lines. More precisely, they saw, like Deleuze observing Bacon's paintings, a shifting sequence or series (and not simply a term in a series), which related areas to lines. Their diagrams were viewed at diverse levels, in different orders, or in different domains, including those of two dimensions and of one dimension.

There's obviously no manual or optical procedure equivalent to this view. This view requires a haptic eye. The haptic eye grew out of the material catastrophic fact that a very thin hand drawn figure might look like a line, and that an area can in fact, pace Aristotle's Physics, be exhausted by many hand-drawn adjacent lines. The haptic eye grew out of the fact that 'vulgar' practitioners confounded numbers and magnitudes. The haptic eye transformed this confusion into a regulated and limited practice of figures as lines. The haptic eye turned these catastrophes and possibilities into matters of fact, a stratified view of geometric magnitudes, which no other sense or reason establish.

The haptic eye is the non-algebraic and non-arithmetic organ, which operates a Greek geometry of hybrid, but entirely not abstractly quantitative, geometric entities. Greek mathematics is tinged by hybridity, and the integrity of the principle that magnitudes of different dimensions are distinct is weak. But this does not bring about algebra, because there is much more to algebra than the weakening of the division between dimensions. The difference between Greek geometry and algebra has as much to do with forms of inscription, means of 
production and organisation of knowledge, as well as with the means of perception and embodied genesis subsumed under haptic vision.

\section{Last motion: The Aura}

In the above discussion I did not give Greek mathematical text the attention it merits in an analysis of Greek geometry. I can't comment here on the crucial role of the text (on top of that of haptic vision) in turning special diagrams into vehicles for general proofs, as analyzed in Netz (1999). But I will consider here a different aspect of Greek use of words, which is related to the problem of the division between different kinds of magnitudes, and will provide us with another trajectory to haptic vision.

The relevant case study is the 'hero' of Netz (2004b). Netz conducts a detailed and deep analysis of Archimedes' use of a strange idiosyncratic expression, which he loosely translates as the figure on line. This idiosyncratic expression literally sounds like 'figure multiplied by line', but Netz carefully establishes that it is in fact used geometrically, as the solid whose base is the figure and height is the line, and carries no arithmetical meaning for Archimedes (Netz, 2004b, Ch.II,§2.5).

But why did Archimedes use a phrase that suggests a hybrid treatment of magnitudes as multipliable numbers? Netz' explanation is that Archimedes did not have a compact non-confusing textual formula for the relevant instance, so he chose to import an expression from the register of calculation to the register of geometry. But the result was a new configuration of registers, a new intersection of contexts (Netz, 2004b, 111). According to Netz, this textual choice and interaction of contexts led Eutocius, a later commentator, to produce a somewhat algebraised form of geometry.

Eutocius set out to regularise the use of Archimedes' idiosyncrasies. This canonisation of Archimedes has meant that the Archimedean idiosyncratic formula lost its marginality and has become for Eutocius a natural practice, sanctioned by the authority of Archimedes (Netz, 2004b, 120). Archimedes wishes to mark a piece of text, to endow it with its own distinctive aura. He therefore makes it different — and this difference leads on 
to the possibility of mathematical change (Netz, 2004b, 114). Archimedes' 'signature term' has become a replicable formula, and the aura has become a law of authority. We cannot get very much closer to an explicit manifestation of différance and catastrophe as forces in the production of knowledge

Archimedes, according to Netz, used a certain idiosyncratic terminology, which, in a sense is incommensurable with other approaches - and so with its "aura" it is somehow inapproachable (Netz, 2004b, 59). Netz' concept of aura is taken from Walter Benjamin. In his Work of art in the age of its reproducibility, Netz explains, Benjamin claims that historically, works of art were singular objects surrounded by an "aura" ... which derived from their very singularity. Archimedes' aim is reconstructed by Netz as precisely to create this special irreplaceable object ... this is what the audience of the mathematical proof had expected, in Antiquity, from the geometer (Netz, 2004b, $58-59)$.

Now both signature and aura have much more to them than Netz explicitly declares. I will not dwell on signatures, which, as Derrida shows, have a complex status between name and thing, between a mark of presence and a mark of absence. ${ }^{17}$ But given its force of change and its importance for the audience of Greek geometers, let's conclude by considering this aura, as it can lead us to understand the haptic vision and the Figure from another direction.

Netz is right in observing that Benjamin marks the aura as uniqueness (Benjamin, 1996-2003, III,105). But he further marks it as that which is never entirely severed from its ritual function (Benjamin, 1996-2003, III,105) (perhaps like the religious signification of mathematics for the Pythagoreans), and as that which is bound to an object's presence ... there is no facsimile of the aura (Benjamin, 1996-2003, III,112) (perhaps like some of Einstein's signs and images, which cannot quite yet be reproduced at will).

When Benjamin goes on to comment on the aura in Some Motifs in Baudelaire, the aura becomes the associations which, at home in the mémoire

\footnotetext{
${ }^{17}$ Derrida (See 1984) and the final section of Signature, Event, Context in Derrida (1988)
} 
involontaire, tend to cluster around an object of perception (Benjamin, 1996-2003, IV,337). There we also find Benjamin's most complete articulation of the aura, stating that Inherent in the gaze, however, is the expectation that it will be returned by that on which it is bestowed. Where this expectation is met ... there is an experience [erfahrung] of the aura in all its fullness ... To experience the aura of an object we look at means to invest it with the ability to look back at us. This experience corresponds to the data of mémoire involontaire. Benjamin's quote from Proust clarifies the locus of this mémoire involontaire. Proust writes that some people believe that monuments and pictures appear only through a delicate veil which centuries of love and reverence on the part of so many admirers have woven about them. This chimera ... would become truth if they related it to the only reality that is valid for the individual - namely, the world of his emotions (Benjamin, 1996-2003, IV,338-339). In fact, Proust's mémoire involontaire is much closer to forgetting than what is usually called memory (Benjamin, 1996-2003, II,238). It requires the viewer to enter the world of the internal monologue, the not yet reproducible mémoire involontaire, which is of a different time than that where associative play is sufficiently established and can be reproduced at will and communicated to others. In other words, it requires the viewer to sense what generates a Figure: the interaction of a coded geometric diagram and the non-replicable catastropic marks that it suffers from whatever is in the geometer's head, or around him. It requires the viewer to retrace the Figure with her or his embodied haptic eye.

The economy of the gaze is a complex one. We often think of the gaze as having power over its object. At the same time, we think of the gaze as being captured by an object. The experience of the aura is a sense of balance in this economy, which has no objectivity about it. The Figure compels itself upon us to the extent that we have the power to manipulate it with our haptic eye. Indeed, the haptic gaze invests the Figure with a lively dynamism that returns our gaze. This economy of the haptic eye, this logic of Sensation, is perhaps the best articulation of mathematical 
truth. Truth emerges as a balance between our power to manipulate an object and our being compelled by its law.

\section{CONCLUDING REMARKS ON THE RIGOUR OF A MATHEMATICS VIEWED BY A}

\section{HAPTIC GAZE}

(1) None of the issues of Greek mathematics mentioned above (e.g. Book V's treatment of all magnitudes as one-dimensional, or the problem of seeing in diagrams what's not explicitly there) constitutes a gap in the Elements. Greek mathematicians did not criticise the validity of such inferences for hundreds of years. It was no oversight. These observations only become gaps when observed from the point of view of a later mathematics. For the Greeks, who have never learnt such later mathematics, these were no gaps.

(2) - Surely, these 'anachronistic gaps' might have led the Greek to mistakes! - Greek mathematicians could and did make mistakes. However, they were not 'led' to their mistakes by any 'gaps'. Their proof procedures were sound enough to produce consensus and to sustain the relevant scope of application for their claims. Greek results met the viability tests that Greek mathematicians put them to.

(3) Contemporary mathematicians make mistakes as well. The possibility, inprinciple, of formalising proofs is only marginally relevant, because such formalisation constitutes only a small part of how mathematicians verify their claims, and because this practice too allows mistakes to creep in. ${ }^{18}$ Like Greek mathematical practices, contemporary mathematical practices are sound enough to produce consensus and sustain a certain scope of application for their mathematical products.

(4) By 'a certain scope' I mean that two ice cubes and three ice cubes are five ice cubes only as long as one is finished counting before they melt (now imagine doing that with 2 billion and 3 billion ice cubes).

\footnotetext{
${ }^{18}$ See Parikh (1991) for comments by early $20^{\text {th }}$ century leaders of the Italian school of algebraic geometry concerning their own informal mistakes and those of mathematicians who wrote more formally.
} 
(5) The formal logical consistency, which appears to be obtained by contemporary mathematical practices, is simply that: formal logical consistency. It does not guarantee a-priori any privileged access to ideality or reality.

(6) - Isn't it true that if the Greeks had investigated other areas of mathematics, then the above gaps might have had disastrous effects? - It is true that with the Greeks, such disasters didn't occur. ${ }^{19}$

(7) At least, such disasters didn't occur more frequently than ice-cube counting disasters happen today. Which is not to say that they do not occur very often. Contemporary mathematical statistics and economics are replete with such disasters, as well as those epicycles upon epicycles of exact sciences.

(8) For some radical finitists it is a gap that contemporary mathematics does not consider very large numbers as essentially different from smaller ones, or even that contemporary mathematics allows large numbers at all. But this does not make contemporary mathematics any less capable of applying effectively to whatever it is that it applies effectively to, even in the eyes of the finitist.

(9) There's something silly in believing that any instance of three is equivalent to any other. Mathematics most successfully applies to those specific circumstances, where this belief is not so terribly silly.

(10) - But mathematics has an objective, a destination which it strives for. It is from the point of view of this destination that Greek mathematics has gaps. - Netz' description of Greek mathematical work is as follows: One went directly to diagrams, did the dirty work, and when asked what the ontology behind it was, one mumbled something about the weather and went back to work ... That this was at all possible is partly explicable through the role of the diagram,

\footnotetext{
${ }^{19}$ Actually, one such 'disaster' perhaps did occur — the discovery of incommensurable lines. It is believed by some that Greek mathematics was reformed to get around this 'disaster'. But even then, the 'disaster' hadn't affected the 'vulgar' representation of such magnitudes by something like fractions, relying on practically sustainable approximations. This is precisely the point of Wittgenstein's advice to avoid going through the contradiction (Wittgenstein, 1975, 227).
} 
which acted, effectively, as a substitute for ontology (Netz, 1999, 57). Greek mathematics has its own object. It needn't be subordinated to our contemporary objectives and destinations.

(11) Many contemporary mathematicians too would rather talk about the weather than about ontology. But even mathematicians, who do believe that their mathematics is subject to an ontology, produce texts that have much more to them than their ontology permits. ${ }^{20}$

\section{Notes}

${ }^{1}$ For a review of standpoint epistemology and feminist critique of knowledge see Harding (2004), Longino (1999) and the discussions of 'herstory' (while inspired by such approaches, this paper contains no explicit feminist discussion beyond noting that classical Greek geometry appears to have been an almost exclusive men's 'club'). For a discussion of parasitic noise and knowledge formation see Serres (1982).

\section{REFERENCES}

Aristotle. 2004. Posterior analytics. Translated by G.R.G. Mure. Adelaide: ebooks. 〈http://etext.library.adelaide.edu.au/a/aristotle/a8poa/〉

Benjamin, Walter 1996-2003, Selected writings (four volumes). Canbridge, MA \& London: Harvard University Press.

Bogue, Ronald. 2003. Deleuze on music, painting and the arts. London \& NY: Routledge.

Borges, Jorge L. 1962. Ficciones. Translated by A. Bonner. New York: Grove Press. Deleuze, Gilles. 1989. Cinema (two volumes). Translated by H. Tomlison \& R. Galeta. London: The Athlone Press.

Deleuze, Gilles. 1990. Logic of sense. Translated by M. Lester \& C. Stivale. New York: Columbia University Press.

Deleuze, Gilles. 1994. Difference and repetition. Translated by P. Patton. New York: Columbia University Press.

Deleuze, Gilles. 2003. Francis Bacon: The logic of sensation. Translated by D.W. Smith. Minneapolis: University of Minnesota Press.

\footnotetext{
${ }^{20}$ See, for example, my analysis of Gödel's proof in Wagner (2008).
} 
Deleuze, Gilles \& Félix Guattari. 1987. A thousand plateaus. Minneapolis, MN: University of Minnesota Press.

Derrida, Jacques. 1979. Speech and phenomena. Translated by D.B. Allison. Evanston: Northwestern University Press.

Derrida, Jacques. 1984. Signeponge. Translated by R. Rand. New York: Columbia University Press.

Derrida, Jacques. 1988. Limited inc.. Translated by S. Weber \& J. Mehlman Evanston, Il.: Northwestern University Press.

Derrida, Jacques. Edmund Husserl's Origin of Geometry, an Introduction. Translated by J.P. Leavy Jr. Lincoln, NE: University of Nebraska Press.

Duffy, Simon (editro). 2004. Virtual mathematics. Manchester: Clinamen Press.

Fried, Michael N. \& Sabetai Unguru. 2001. Apollonius of Perga's Conica: text, context, subtext. Leiden: Brill.

Gadamer, Hans G. 1975. Truth and method. Translated by G. Barden \& J. Cumming. New York: Seabury Press.

Grosholz, Emily R. 2007. Representation and productive ambiguity in mathematics and the sciences. Oxford: Oxford university press.

Hadamard, Jacques. 1973. The mathematician's mind. Princeton, NJ: Princeton University Press.

Harding, Sandra. 2004. "Rethinking feminist standpoint epistemology: What is 'strong objectivity'?" In The feminist standpoint theory reader: intellectual and political controversies, edited by S. Harding, 127-140. New York: Routledge.

Heath, Thomas L. 1956. The thirteen books of Euclids Elements. New York: Dover Publications.

Joyce, David E. 1988. Euclid's Elements. 21 March 2009. ¡http://aleph0.clarku.edu/ djoyce/java/elements/elements.htmli.

Knorr, Wilbur R. 1975. The evolution of the Euclidean elements. Dordrecht: D. Reidel Pub. Co.

Latour, Bruno. 2008. "The Netz-works of Greek deductions." Social studies of science 38(3):441-459 
Lefebvre, Muriel. 2002. "Construction et déconstruction des diagrammes de Dynkin." Actes de la recherche en sciences sociales 141-142:121-124

Longino, Helen E. 1999. "Feminist epistemology." In The Blackwell guide to epistemology, edited by J. Grecco \& E. Sosa, 327-353. Malden, MA: Blackwell.

Mueller, Ian. 1981. Philosophy of mathematics and deductive structure in Euclid's Elements. Cambridge, MS.: MIT Press.

Netz, Reviel. 1998. "Greek mathematical diagrams: their use and their meaning." For the learning of mathematics 18(3):33-39.

Netz, Reviel. 1999. The shaping of deduction in Greek mathematics. Cambridge: Cambridge University Press.

Netz, Reviel. 2004a. "The limits of text in Greek mathematics." In History of science, history of text, edited by K. Chemla, 161-176. Dordrecht: Springer.

The limits of text in Greek mathematics. 2004b. The transformation of mathematics in the early mediterranean world. Cambridge: Cambridge University Press.

Parikh, Carol. 1991. The unreal life of Oscar Zariski. Boston: Harcourt, Brace Jovanovich.

Radford, Luis. 2006. "Algebraic thinking and the generalization of patterns: a semiotic perspective." In Proceedings of the 28th conference of the international group for psychology of mathematics education, north American chapter, edited by S. Alatorre, J. Cortina, M. Sáiz, \& A. Méndez, 1:2-21. Mérida: Universidad Pedaggica Nacional.

Serres, Michel. 1982. The parasite. Translated by Lawrence R. Schehr. Baltimore, MA \& London: John Hopkins University Press.

Sia, Xin Wei. 2004. "Differential geometrical performance and poiesis." Configurations 12:133-160

Starobinski, Jean. 1979. Words upon words: the anagrams of Ferdinand de Saussure. Translated by O. Emmet. New Haven: Yale University Press.

Steinbeck, John. 1962. Travels with Charley: in Search of America. New York: Viking Press. 
Taisbak, Christian M. 2003. Euclid's Data: the importance of being given. Copenhagen: Museum Tusculanum Press.

Williams, James. 1997. "Deleuze on J.M.W. Turner: catastrophism in philosophy?" In Deleuze and philosophy, the difference engineer, edited by K.A. Pearson, 233246. London \& NY: Routledge.

Unguru, Sabetai. 1975. "On the need to rewrite the history of Greek mathematics." Archive for the history of exact sciences 15:67-114

Unguru, Sabetai. 1979. "History of ancient mathematics: some reflections on the state of the art." Isis 70:555-564

Unguru, Sabetai \& David Rowe. 1981-1982. "Does the quadratic equation have Greek roots." Libertas mathematics 1 (1981):1-49, 2 (1982):1-62

Vitrac, Bernard. 1994. Les Eléments, Vol. 2: livres V-IX. Paris: Presses Universitaires de France.

Wagner, Roy. 2008. "Post structural readings of a logico-mathematical text." Perspectives on science 16(2):196-230

Wittgenstein, Ludwig. 1975. Lectures on the foundations of mathematics. Edited by C. Diamond. Chicago: The University of chicago Press.

Zeuthen, Hieronymus G. 1965. Die Lehre von den Kegelschnitten im Altertum. Hildesheim: G. Olms. 